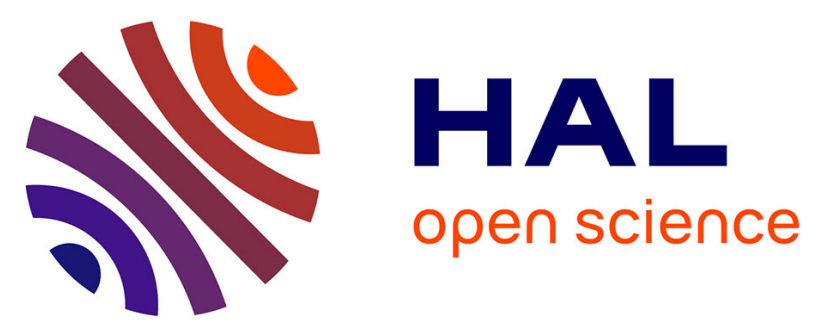

\title{
The consumption of locally-produced foodstuff: an important parameter of the radiological exposure for population living in the vicinity of French nuclear facilities
}

\author{
V. Durand, E. Leclerc, Ph. Renaud
}

\section{To cite this version:}

V. Durand, E. Leclerc, Ph. Renaud. The consumption of locally-produced foodstuff: an important parameter of the radiological exposure for population living in the vicinity of French nuclear facilities. Radioprotection, 2018, 53 (3), pp.185-191. 10.1051/radiopro/2018027 . hal-02904124

HAL Id: hal-02904124

https://hal.science/hal-02904124

Submitted on 21 Jul 2020

HAL is a multi-disciplinary open access archive for the deposit and dissemination of scientific research documents, whether they are published or not. The documents may come from teaching and research institutions in France or abroad, or from public or private research centers.
L'archive ouverte pluridisciplinaire HAL, est destinée au dépôt et à la diffusion de documents scientifiques de niveau recherche, publiés ou non, émanant des établissements d'enseignement et de recherche français ou étrangers, des laboratoires publics ou privés. 


\title{
The consumption of locally-produced foodstuff: an important parameter of the radiological exposure for population living in the vicinity of French nuclear facilities
}

\author{
V. Durand ${ }^{1, *}$, E. Leclerc ${ }^{2}$ and Ph. Renaud ${ }^{3}$ \\ ${ }^{1}$ IRSN, Health and Environment Division - Health, Emergency Response Organization Department, 31 avenue de la Division Leclerc, \\ BP 17, 92262 Fontenay-aux-Roses Cedex, France. \\ 2 Andra, Service Sûreté en Exploitation et Environnement, Direction Sûreté Environnement et Stratégie Filières, 1-7 rue Jean Monnet, \\ 92298 Châtenay-Malabry Cedex, France. \\ ${ }^{3}$ IRSN, Health and Environment Division - Environment, CEN Cadarache, 13115 Saint-Paul-lès-Durance, France.
}

Received: 9 February 2018 / Accepted: 3 July 2018

\begin{abstract}
Either in normal or post-accidental situations, the ingestion of locally-produced foodstuffs, potentially contaminated, is one of the main exposures to the population living in the vicinity of nuclear facilities. For this reason, the French Institute for Radioprotection and Nuclear Safety has developed a specific methodology and has carried out surveys on dietary habits of some populations concerned. This study presents the methodology used for local food surveys, the amount consumed and how much food is produced locally. The results from the 6 surveys already done show that food surveys even if conducted with a specific aim as impact assessments provide further in-depth understanding of the food habits of local residents. There are still local specific population groups that have a high level of "home-consumption" for products more sensitive to contamination. For leafy vegetables and milk (products highly sensitive to contamination), home-consumption rates vary widely from one region to another from 76 to more than $90 \%$ and from 1 to $17 \%$ respectively. Specifically for the Andra survey carried out in a rural area in the North-East of France, self-sufficiency had reached $100 \%$ for a few products (game meat for example).
\end{abstract}

Keywords: radiological exposure / food consumption / locally-produced foodstuff / food survey / statistical analysis

\section{Context}

The contamination of the environment by a radioactive release (in normal or accidental situations) should affect locally-produced foodstuffs. One of the main radiological exposures pathways of people living in the vicinity of a nuclear site is the potential intake of radionuclides linked to the ingestion of locally produced foodstuff contaminated by the radioactive releases. This exposure and dosimetric impact of populations is proportional to the contamination level of the foodstuffs and to the ingested quantities (Parache et al., 2011a, 2011b; Renaud et al., 2015). Otherwise, the different kinds of agricultural products are more or less sensitive to the radioactive contamination of the environment. Leafy-vegetables for example are well-known to present the highest contamination levels in case of atmospheric release. So the quantities consumed of each kind of foodstuff must be considered. The categories of foodstuffs considered in national

\footnotetext{
* Corresponding author: vanessa.durand@irsn.fr
}

survey do not match at all with those which must be discriminated for their radiological sensitivity, as leafyvegetables for example. Moreover, these national surveys do not provide information about the part of the consumption which is locally produced. And this part depends strongly of the kind of foodstuff locally produced, so to the kind. Finally, some of them are outdated.

Doses from food ingestion depend mainly on:

- locally sourced food in the population's diet (degree of self-sufficiency, in the broadest sense);

- the nature of the food produced locally (leafy vegetables, dairy products...);

- the season in which the radioactive release occurs in the case of accident.

Regarding the doses received shortly after the occurrence of an accident, special attention should be paid to the proportion of fresh produce (leafy vegetables and dairy products) consumed in the diet (regarding the short period of decrease of some radionuclides). Indeed, during this period, the contribution of other food products (meat, canned milk, 
soft cheeses, cereal products...) is low and will become progressively significant later. National surveys currently available for France (Bertrand, 1993; Volatier, 2000; Lafay, 2009) are not very informative on this matter and the available data are now often outdated. Given the variety of diets across France, it would be appropriate to conduct investigations locally, around the different nuclear sites with a focus on local agricultural products themselves as well as their distribution channels.

The objective of this study is to describe the dietary habits of the most exposed population living near a nuclear site (up to several tens of kilometres): the population likely to have a high consumption of locally-produced foodstuff potentially contaminated either by authorized routine releases or in case of (or after) an accident.

\section{Material and method}

For local surveys conducted by IRSN (Fig. 1 and Tab. 1), self-sufficiency is defined as the consumption of foodstuffs produced locally or picked by the consumer and of foodstuffs from local sources (less than or equal to $50 \mathrm{~km}$ ). These foods are fruits and vegetables from privately owned garden and orchards, meat and poultry from individual farms, sea food products, hunting and gathering. Insofar as we are interested in pollution which may occur in localized areas, it seemed necessary to include, in addition to home-consumption food, food purchased from local farms or redistributed by local producers as poultry products or milk or cheese. Seasonal variations also play a major role in the consumption of foodstuffs from local sources. The consumption of vegetables and dairy products and seasonal variations in production and consumption of these products must be also taken into account. Concerning national surveys and those designed especially for populations living near nuclear facilities, the method of consumer notebooks is usually chosen (Durand et al., 2006).

Each survey concerns a sample of 150 to 200 people who disposes a kitchen garden or orchard or barnyard or is consumer of local food products. (Descamps and Guillet, 2003). A specific protocol has been developed to correspond at this aim. This protocol takes into account: (1) the informative nature of the results obtained for the first study (Parache, 2010), (2) national trends in the population's food habits (Bertrand, 1993; Volatier, 2000; Lafay, 2009), and (3) the necessity to ensure that the protocol could be reproduced in the future and in other places. This approach consists in several stages: (a) defining the population group to be surveyed and the area covered by the study, (b) choosing the survey period and seasonal variations in home-consumption habits, (c) providing information to the inhabitants surveyed and drawing up a survey questionnaire in the form of a weekly homeconsumption notebook and (d) the survey and statistical processing of the collected data.

The membership of families in the survey protocol considered to be time consuming (intelligence daily questionnaire) based on two essential elements: (1) time for exchanges and explanation to the families, (2) the checking of the collected information in collaboration with family to avoid an unusable questionnaire. This type of survey needs also the expertise and human relationships abilities. To take into

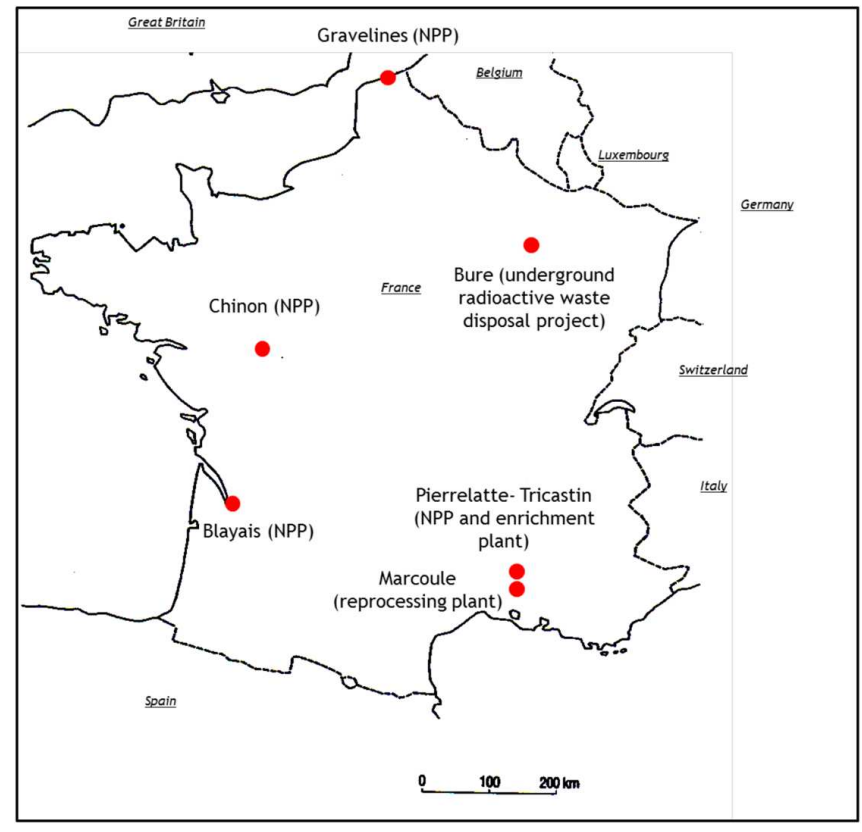

Fig. 1. Location at which surveys were conducted.

account all foods mentioned in consumer notebooks in foodstuff categories used for impact assessments, some adjustments were made (Tab. 2).

\section{Results}

\subsection{Food ration (Fig. 2 and Tab. 3)}

Figure 2 presents the quantities consumed of each kinds of foods, provided by the different surveys. The results are consistent. The different kinds of foodstuff are consumed with the same proportions and contribute with similar proportion to the whole consumption. However, quite important variations can be observed. It is notably the case for fruit-vegetables with consumption rates ranging from 50 (Gravelines) to $165 \mathrm{~kg} / \mathrm{y}$ (Tricastin), and fruits $(45 \mathrm{~kg} / \mathrm{y}$ and $100 \mathrm{~kg} / \mathrm{y}$ for Gravelines and Tricastin respectively). Inversely, the consumption of potatoes is higher close to Gravelines $(75 \mathrm{~kg} / \mathrm{y})$ than in the vicinity of Tricastin $(40 \mathrm{~kg} / \mathrm{y})$. These gaps are linked to well-known differences between the agricultural practices and food habits of the two corresponding regions. It appears also that the total quantity of seafood (fish, shellfish and crustaceans) consumed by people living close to the sea (Gravelines, Blayais) is about 35 to $40 \mathrm{~kg} / \mathrm{y}$ whereas it is only 12 to $22 \mathrm{~kg} / \mathrm{y}$ in other sites (located away from the sea).

And finally, the food ration varies from $543 \mathrm{~kg} / \mathrm{y}$ (Chinon) to $700 \mathrm{~kg} / \mathrm{y}$ (Tricastin). Table 3 presents the mean values of the quantities consumed for each foodstuff categories on the basis of the results of the different surveys. The minimum ( $\min$ ) and maximum (max) values and the name of the surveys corresponding to the min and max values are also given for information. Indeed, for vegetables products (root and fruits specifically) and fruits products, the gaps between min and max values are about a factor 2 and more. 
Table 1. Food surveys conducted by IRSN near French nuclear sites.

\begin{tabular}{lllllr}
\hline Survey & Location & Date & $\begin{array}{l}\text { Collaboration } \\
\text { (financial or technical) }\end{array}$ & $\begin{array}{l}\text { Response } \\
\text { rate (\%) }\end{array}$ & $\begin{array}{l}\text { Number of people } \\
\text { surveyed }\end{array}$ \\
\hline Chinon & Loire Valley & Summer 2008 & EDF, ADEME & 72 & 217 (88 households) \\
Tricastin & Rhone Valley & Summer 2004 & AREVA, ADEME & 51 & 182 (76 households) \\
Marcoule & Rhone Valley & Summer 2010 & CEA & 90 & 216 (83 households) \\
Gravelines & North sea & Summer 2011 & ADEME, CLI & 80 & 252 (82 households) \\
Blayais & Gironde Valley & Summer 2012 & ADEME & 93 & 315 (119households) \\
OPE-Bure & Est of France & Summer 2013 & ANDRA & 89 & 308 (106 households)
\end{tabular}

${ }^{*}$ The Tricastin survey also aimed to see seasonal changes in feeding practices. The survey has been conducted during the summer and fall 2004 and during the winter and spring 2005. To compare, only the results of the summer 2004 will be presented here.

${ }^{* *}$ The response rate is the percentage of people from the sample who have answered.

Table 2. Correspondence between foodstuff categories used for impact assessments and those from the treatment of local surveys.

\begin{tabular}{ll}
\hline Foodstuff categories IRSN & Foodstuff categories from the treatment \\
\hline Leafy vegetables & Fresh leafy vegetables + wild asparagus + aromatic plants \\
Root vegetables & Fresh root vegetables \\
Potatoes & Potatoes \\
Fruit vegetables & Fresh fruit vegetables + dried vegetables \\
Fruits & Fresh fruits + nuts + dried fruits + fruit preserves and jams \\
Mushrooms & Mushrooms and wild mushrooms \\
Cereal products & Rice + bread and rusk + other cereals \\
Milk & Milk \\
Other milk products & Cheese + butter + other milk products \\
Meat & Beef, veal, sheep and pork meat + sausage + wild animals + poultry + rabbits + snails \\
Eggs & Eggs \\
Fish & Fish \\
Seafood (shellfish and crustaceans) & Shellfish and crustaceans \\
\hline
\end{tabular}

${ }^{*}$ For Marcoule, Gravelines, Blayais and Bure surveys (for Chinon and Tricastin sites, seafood category is with fish category).

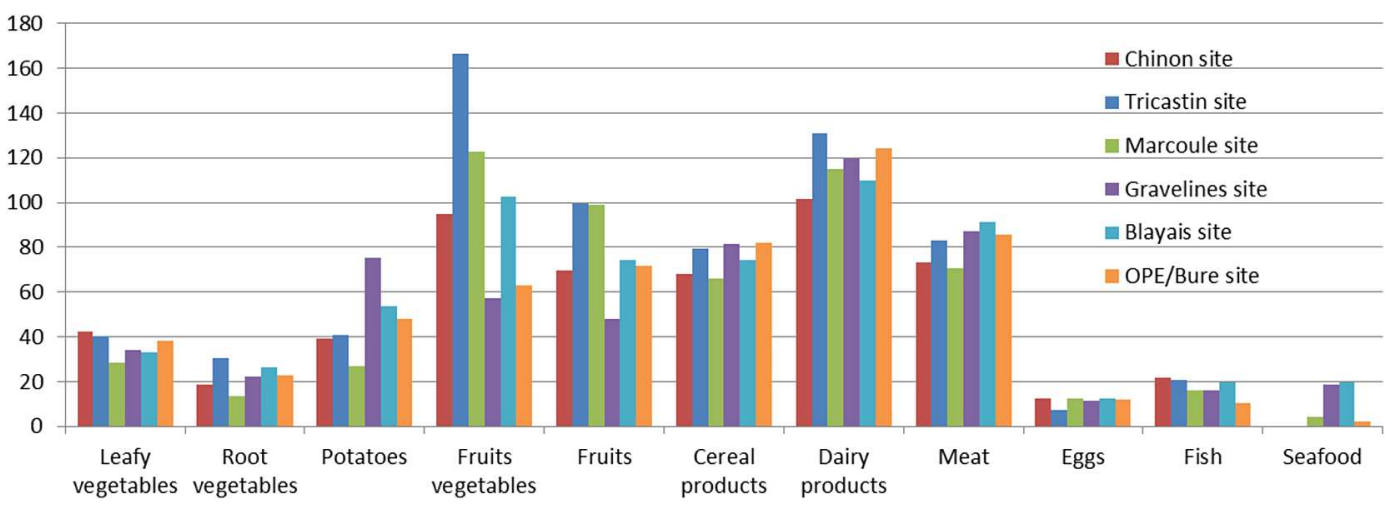

Fig. 2. Food intake (kg/y.person) for population living near the Chinon, Marcoule, Tricastin, Gravelines, Blayais and Bure sites.

\subsection{Self-sufficiency (Tabs. 4 and 5)}

In these studies, it was confirmed that targeted population of the survey have high rates of home-consumption, of around 70 to more than $90 \%$ for different food categories (Tab. 4). Home consumption of some specific natural food products can reach a rate of $100 \%$ (wild animals and mushrooms, fresh water fish for example) (Appendix 1). For plant crops, the results are of the same order of magnitude at these sites, with the exception of fruiting vegetables and fruits, consumed and locally-produced in significantly larger quantities by the population of Tricastin (Tabs. 3 and 4). On the other hand, home-consumption rates are higher in Bure in the case of meat, eggs and especially dairy products ( $17 \%$ for milk). The population surveyed near the Chinon, Marcoule, Gravelines and Blayais sites averages between those of Tricastin and that 
Table 3. Mean, min and max values of the quantity consumed for each foodstuff categories from the different local surveys, and name of the surveys corresponding to the min and max values in $\mathrm{kg} / \mathrm{y}$.

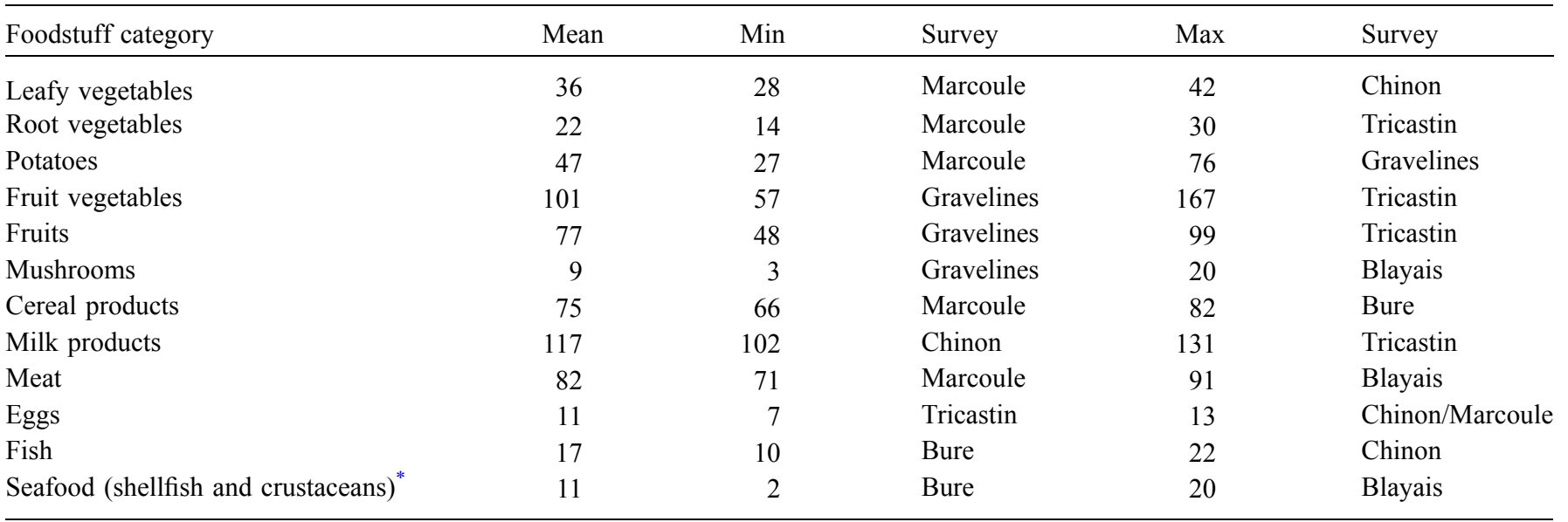

${ }^{*}$ For the following sites: Marcoule, Gravelines, Blayais and Bure. The distinction fish / shellfish and crustaceans was not done in previous surveys

Table 4. Home-consumption rate ( $\%$ of the total solid or liquid intake) for each foodstuff categories from the different local surveys.

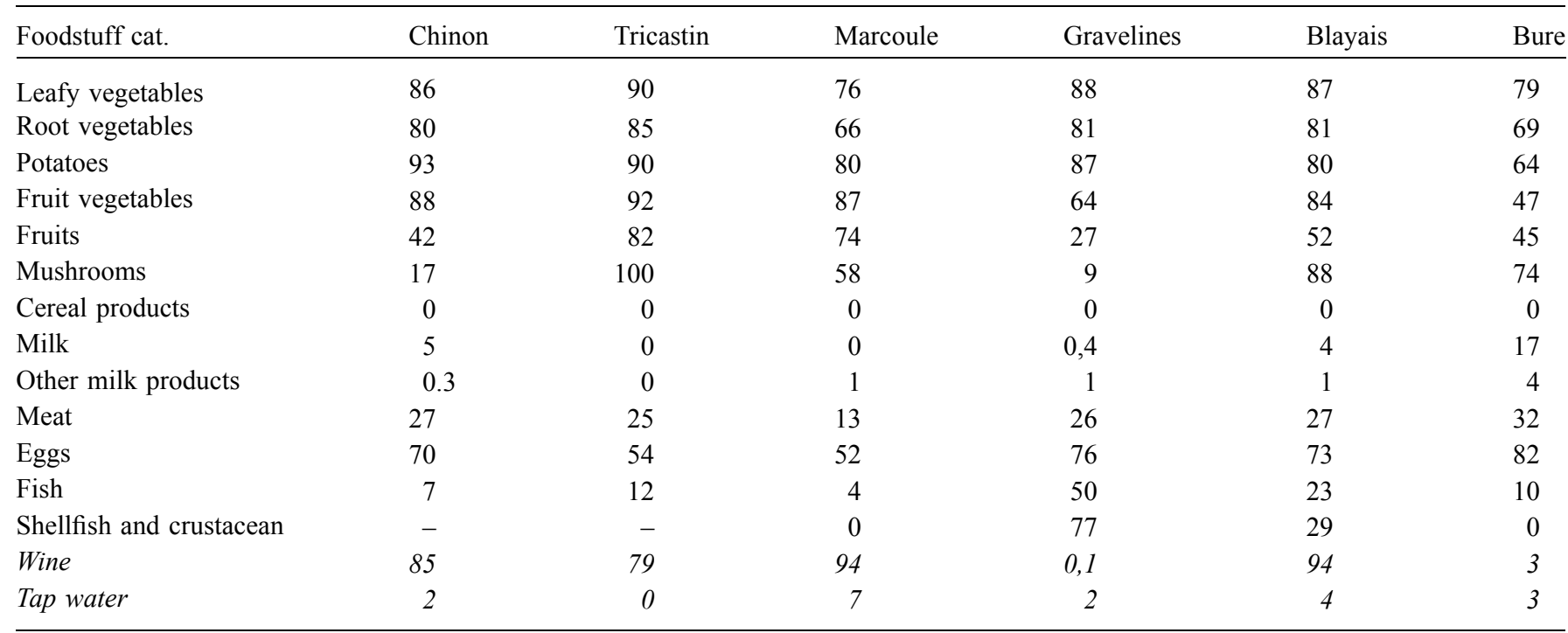

Table 5. Mean, min and max values of the quantity home-consumed for each foodstuff categories from the different local surveys, and name of the surveys corresponding to the min and max values in $\mathrm{kg} / \mathrm{y}$.

\begin{tabular}{|c|c|c|c|c|c|}
\hline Foodstuff cat. & Mean & Min & Survey & Max & Survey \\
\hline Root vegetables & 17 & 9 & Marcoule & 26 & Tricastin \\
\hline Fruit vegetables & 82 & 29 & Bure & 153 & Tricastin \\
\hline Fruits & 45 & 13 & Gravelines & 81 & Tricastin \\
\hline Meat & 21 & 9 & Marcoule & 27 & Bure \\
\hline Eggs & 8 & 4 & Tricastin & 10 & Bure \\
\hline Fish & 3 & 1 & Marcoule & 8 & Gravelines \\
\hline Seafood (shellfish and crustaceans) ${ }^{*}$ & 5 & 0 & Marcoule/Bure & 14 & Gravelines \\
\hline
\end{tabular}

\footnotetext{
${ }^{*}$ For the following sites: Marcoule, Gravelines, Blayais and Bure. The distinction fish / shellfish and crustaceans was not done in previous surveys.
} 
Table 6. Consumption and home consumption values used for the gardener village reference group (Mean, min, max and 95th percentile values of the quantity consumed and home-consumed for each foodstuff categories).

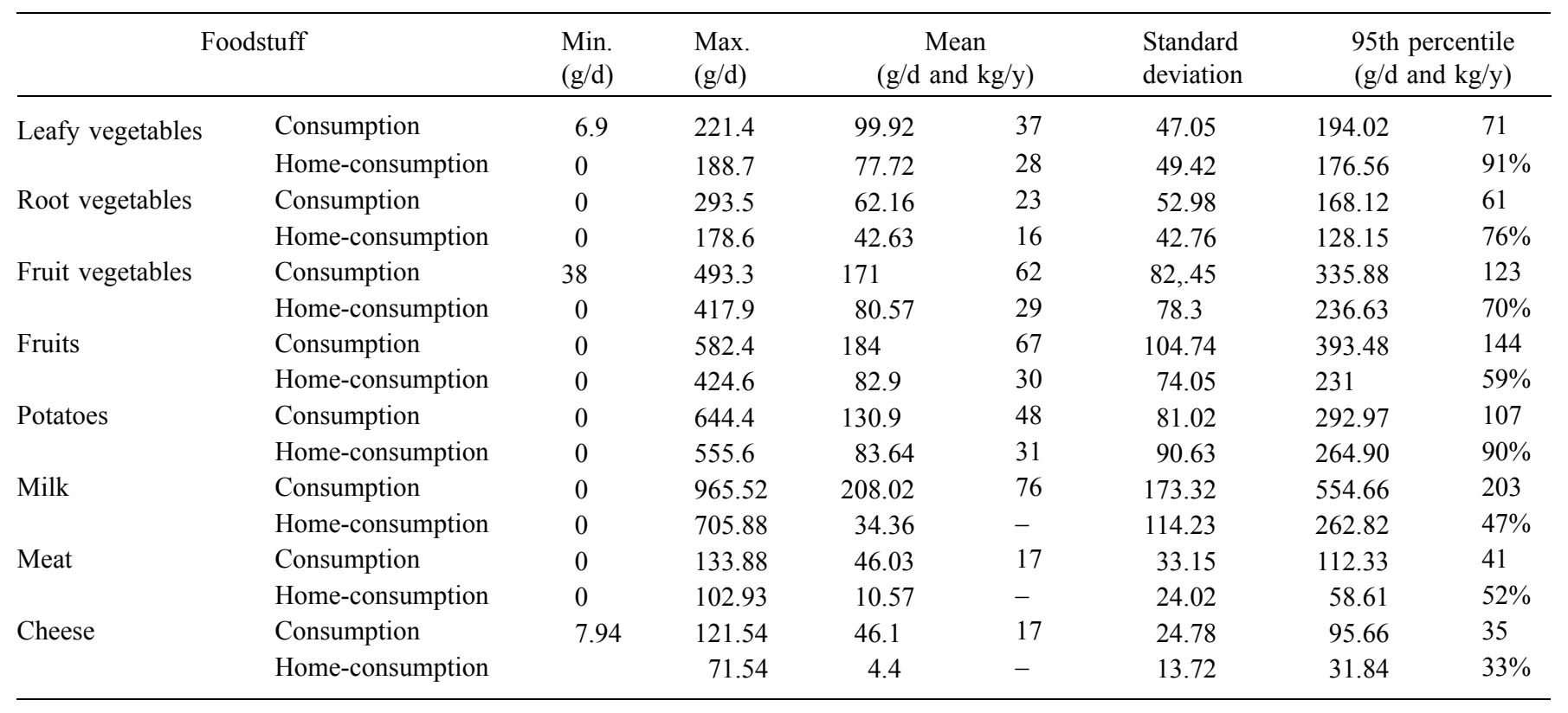

of Bure. The home-consumption is finally more important for people living close to the sea (Blayais and Gravelines): respectively 26 and $64 \%$ of home-consumption of seafood (fish, shellfish and crustacean) against 4 to $12 \%$ for people in sites located away from the sea. This finding could be compared with local production in each of the five regions (Parache, 2011; Parache et al., 2011b; Parache, 2012, 2013, 2014; Leclerc, 2014) and (Andra, 2018; Leclerc et al., 2014).

In its report on the gardens (Schwartz et al., 2013), the ADEME explains that gardening concerns $51 \%$ of rural families. This practice concerns only $20 \%$ of families living in a city of more than 100000 inhabitants. This helps to explain the levels of home-consumption of fruit, vegetables and potatoes observed in local surveys. According to this report, nowadays, retired people are more likely to use gardening than before. Among the farmers, 74\% have a kitchen-garden and the total rises to $93 \%$ for farmers aged between 55 and 65 years in contrast to workers and employees, with averages respectively $40 \%$ and $25 \%$. The rurality of the population has no influence on the home-consumption of fruit and vegetables (ParacheDurand and Grandjean, 2015). However, it can affect the home-consumption of livestock products (meat, milk and eggs). The very rural nature of Bure site, could explain the observed levels for home-consumption of these products. In many cases, rates of home-consumption vary from one food category to another. The region of origin is also of importance.

Table 5 presents the mean values of the home-consumed quantities for each foodstuff categories on the basis of the results of these different surveys. The minimum and maximum are also given for information. For leafy vegetables, the gap between min and max values is less than a factor of 2. For eggs, it is about 2. And for all other foodstuff categories, the gaps are between factors of 3 to 8 . It is linked to a very high homeconsumption rate of fruit vegetables and fruits from the Tricastin survey and to a high home-consumption rate of seafood products from the Gravelines survey.

\subsection{Use of statistical analysis}

Sensitives analysis can be made on human behaviour considering statistical analysis.

Beyond the use of food survey results as mean values in risk and impact assessment, the use of other results from a statistical analysis if available can be useful. If the sample size is large enough, some statistical analysis had allowed extracting statistical distribution of data, standard deviation and percentiles. Indeed, some very specific behaviour as high consumer of vegetables or dairy products can be pointed out for upper bound impact in risk assessments.

In the case of Bure survey, for example, 95th percentile values as specified in Table 6, are used to represent realistic but specific behaviour as high consumer of dairy products or kitchen garden products (raw data presented in Appendix 1).

\section{Conclusion}

These studies show that food surveys, even if conducted with the specific aim of dosimetric impact assessments, provide further in-depth understanding of the food habits of small groups representative of a mainly rural population. Taking into account local supply systems reach to more realistic data compared to national data. These surveys show that there are still local specific population groups that have a high level of "self-consumption" for local or regional products. This home-consumption includes specifically foodstuff among the more sensitive to a radioactive contamination. Furthermore, the acquisition of "local" data compared to "national scale" data, provides accuracy of the scenarios studied (taking into account variations or regional characteristics, for example) and thus promotes the credibility of impact assessment studies. Finally, local food surveys show that the season and the region can have a strong influence on the degree 
of self-sufficiency and, consequently, the impact that would be received by certain categories of population living near those industrial sites in case of an accident or for authorized routine releases. This is a limitation of this article which does not present any figures concerning this aspect. But one of the surveys carried out concerned the four seasons and showed that there was variability according to the production seasons (Parache, 2010). Specifically, during the summer, the consumption of fruits and fruit-vegetables was much more important.

Current practices in health risk assessment for impact studies shows that in the absence of such specific data, the practitioner who wishes to introduce the concept of selfconsumption in its exposure scenarios, most often choose between two extremes: $100 \%$ or $0 \%$ of self-consumption, and this for all food categories. Yet, the results gained through this study confirm the variability of this important parameter of the sensitivity of population exposed. Despite the changing of eating habits (supermarkets, ready meals), there are still groups of people with high consumption practices whose variability is due both to the categories of food and to the geographic area.

\section{References}

Andra. 2018. Long-term Environmental Research Monitoring and Testing System (OPE), https://www.andra.fr/cigeo.

Bertrand M. 1993. Consommation et lieux d'achat des produits alimentaires. INSEE Report ISBN 2-11-066133-X.

Descamps B, Guillet F. 2003. Enquête alimentaire dans trois secteurs de la Basse Vallée du Rhône: Codolet, Tresques, Camargue. Consommation/Autoconsommation, Radioprotection 39, $299-322$.

Durand V, Vray F, Mercat C. 2006. Improving the knowledge of exposure by ingestion thanks to food surveys. In: International ISEE/ISEA Conference, Paris, 2-8 September 2006.

Lafay L. 2009. Étude Individuelle Nationale des Consommations Alimentaires 2 (INCA 2) (2006-2007). AFSSA Report.

Leclerc E. 2014. Enquête alimentaire sur la zone OPE du centre Meuse/Haute-Marne de l'Andra - Synthèse des résultats. Rapport Andra SUR NT ASSE No. 14-0009.

Leclerc E, d'Arbaumont M, Verron J-P, Goldstein C, Cesar F, Dewonck S. 2014. Andra Environmental Specimen Bank: archiving the environmental chemical quality for long-term monitoring, Environ. Sci. Pollut. Res., Special issue, DOI: 10.1007/s11356-014-2924-6.

Parache V. 2010. Projet SENSIB - Résultats de l'enquête alimentaire autour du site de Pierrelatte-Tricastin (2004-2005). IRSN report No. 2010-31.

Parache V. 2011. Projet SENSIB - Enquête alimentaire autour du site nucléaire de Marcoule (2010) : Méthode et Résultats. IRSN report No. 2011-07.

Parache V. 2012. Projet SENSIB - Enquête alimentaire autour du site nucléaire de Gravelines (2011): Méthode et Résultats. IRSN report No. 2012-09.

Parache V. 2013. Enquête alimentaire autour du site nucléaire du Blayais (2012): Méthodologie, résultats et comparaison avec d'autres données. IRSN report No. 2013-02.

Parache V. 2014. Enquête alimentaire sur la zone OPE du centre Meuse/Haute-Marne de l'Andra: Méthodologie et Résultats. IRSN report No. 2014-08.

Parache V, Roussel-Debet S, Renaud P. 2011a. Studying eating habits in the vicinity of French nuclear power plants and dosimetric sensitivity due to ingestion. In: International Conference on Radioecology and Environmental Radioactivity, Hamilton, 19-25 June 2011.

Parache V, Maurau S, Mercat C. 2011b. Food surveys for assessing health risks near industrial sites: methodology and main results near two nuclear sites. Environnement Risques et Santé 10, 105-119. DOI: 10.1684/ers.2011.0434.

Parache-Durand V, Grandjean G. 2015. Régionalisation des résultats des enquêtes alimentaires réalisées à proximité de sites nucléaires Étude sur le littoral de la Manche, les vallées du Rhône et de la Loire. IRSN report No. 2015-06.

Renaud R, Parache V, Roussel-Debet S. 2015. Internal doses of French adult population linked to the intake of radionuclides from the decay-chains of uranium and thorium by foodstuffs ingestion. Radioprotection, DOI: 10.1051/radiopro/2014034.

Schwartz C et al. 2013. Jardins potagers : terres inconnues ? ADEME (Agence nationale de l'environnement et de la maîtrise de l'énergie), avril 2013. EAN imprimé : 9782759807239.

Volatier JL. 2000. Enquête INCA (Individuelle et Nationale sur les Consommations Alimentaires). Rapport CREDOC, AFSSA and Ministère de l'Agriculture.

Cite this article as: Durand V, Leclerc E, Renaud $\mathrm{Ph}$. 2018. The consumption of locally-produced foodstuff: an important parameter of the radiological exposure for population living in the vicinity of French nuclear facilities. Radioprotection 53(3): 185-191 


\section{Appendix 1 Results for Bure survey}

(Parache, 2014).

\begin{tabular}{|c|c|c|c|c|c|c|}
\hline \multirow[b]{2}{*}{ Food products } & \multicolumn{6}{|c|}{ HOME-CONSUMPTION (g) } \\
\hline & Min. & Max. & Average & Median & \begin{tabular}{|l|} 
coefficient \\
of variation \\
\end{tabular} & $\begin{array}{l}\text { Standarc } \\
\text { variation }\end{array}$ \\
\hline Fresh leafy vegetables & 0.00 & 188.73 & 77.72 & 71.43 & 0.64 & 49.42 \\
\hline Fresh roots vegetables & 0.00 & 178.64 & 42.63 & 31.25 & 1.00 & 42.76 \\
\hline Fresh fruit vegetables & 0.00 & 417.86 & 80.57 & 71.43 & 0.97 & 78.03 \\
\hline \multicolumn{7}{|l|}{ Other vegetables } \\
\hline dried vegetables & 0.00 & 0.00 & 0.00 & 0.00 & & 0.00 \\
\hline potatoes & 0.00 & 555.56 & 83.64 & 75.00 & 1.08 & 90.63 \\
\hline mushrooms of Paris & 0.00 & 0.00 & 0.00 & 0.00 & & 0.00 \\
\hline wild mushrooms & 0.00 & 68.68 & 6.82 & 0.53 & 2.01 & 13.70 \\
\hline wild asparagus and other wild plants & 0.00 & 3.39 & 0.13 & 0.00 & 4.23 & 0.57 \\
\hline aromatic plants & 0.00 & 25.00 & 4.63 & 3.23 & 1.07 & 4.97 \\
\hline Fresh fruits & 0.00 & 424.59 & 82.90 & 71.43 & 0.89 & 74.05 \\
\hline \multicolumn{7}{|l|}{ Other fruit and honey } \\
\hline nuts & 0.00 & 14.61 & 0.21 & 0.00 & 7.41 & 1.58 \\
\hline dried fruits & 0.00 & 0.00 & 0.00 & 0.00 & & 0.00 \\
\hline fruit preserves and jams & 0.00 & 53.85 & 4.77 & 0.00 & 1.99 & 9.50 \\
\hline honey & 0.00 & 27.78 & 2.79 & 0.53 & 2.01 & 5.62 \\
\hline \multicolumn{7}{|l|}{ Meat, Eggs and Fish } \\
\hline beef-veal-horse & 0.00 & 102.93 & 10.57 & 0.00 & 2.27 & 24.02 \\
\hline sheep & 0.00 & 39.11 & 0.90 & 0.00 & 6.14 & 5.52 \\
\hline pork & 0.00 & 125.00 & 12.75 & 0.00 & 2.27 & 28.98 \\
\hline delicatessen & 0.00 & 122.50 & 4.46 & 0.00 & 3.52 & 15.71 \\
\hline game & 0.00 & 89.19 & 13.87 & 4.87 & 1.43 & 19.90 \\
\hline poultry & 0.00 & 203.39 & 22.87 & 0.00 & 1.72 & 39.38 \\
\hline rabbits & 0.00 & 76.92 & 6.51 & 0.00 & 2.14 & 13.96 \\
\hline snails & 0.00 & 92.31 & 2.82 & 0.00 & 3.82 & 10.75 \\
\hline eegs & 0.00 & 93.51 & 26.38 & 24.24 & 0.80 & 21.03 \\
\hline sea fish & 0.00 & 0.00 & 0.00 & 0.00 & & 0.00 \\
\hline river fish & 0.00 & 68.57 & 2.87 & 0.00 & 3.14 & 9.00 \\
\hline shellfish and crustaceans & 0.00 & 0.00 & 0.00 & 0.00 & & 0.00 \\
\hline \multicolumn{7}{|l|}{ Other foods } \\
\hline cow cheeses & 0.00 & 71.54 & 4.40 & 0.00 & 3.12 & 13.72 \\
\hline goat cheeses & 0.00 & 84.75 & 0.96 & 0.00 & 8.63 & 8.31 \\
\hline sheep cheeses & 0.00 & 0.00 & 0.00 & 0.00 & & 0.00 \\
\hline butters & 0.00 & 0.00 & 0.00 & 0.00 & & 0.00 \\
\hline oil & 0.00 & 0.00 & 0.00 & 0.00 & & 0.00 \\
\hline other fat & 0.00 & 17.86 & 0.17 & 0.00 & 10.25 & 1.74 \\
\hline breads and rusks & 0.00 & 0.00 & 0.00 & 0.00 & - & 0.00 \\
\hline other cereals: flour - semolina - pasta & 0.00 & 0.00 & 0.00 & 0.00 & - & 0.00 \\
\hline chocolate & 0.00 & 0.00 & 0.00 & 0.00 & & 0.00 \\
\hline rice & 0.00 & 0.00 & 0.00 & 0.00 & & 0.00 \\
\hline salt & 0.00 & 0.00 & 0.00 & 0.00 & _ & 0.00 \\
\hline sugar & 0.00 & 0.00 & 0.00 & 0.00 & & 0.00 \\
\hline \multicolumn{7}{|l|}{ Liquid } \\
\hline Milk (cow) & 0.00 & 705.88 & 34.36 & 0.00 & 3.32 & 114.23 \\
\hline other dairy products & 0.00 & 0.00 & 0.00 & 0.00 & & 0.00 \\
\hline wine and liqueurs & 0.00 & 88.76 & 1.82 & 0.00 & 6.05 & 11.02 \\
\hline beers & 0.00 & 0.00 & 0.00 & 0.00 & & 0.00 \\
\hline fruit juices and sugary drinks & 0.00 & 116.55 & 7.83 & 0.00 & 2.68 & 20.97 \\
\hline tap water & 0.00 & 1866.67 & 26.52 & 0.00 & 7.63 & 202.23 \\
\hline mineral water & 0.00 & 0.00 & 0.00 & 0.00 & & 0.00 \\
\hline tea - coffee - herbal teas & 0.00 & 6.49 & 0.06 & 0.00 & 10.25 & 0.63 \\
\hline
\end{tabular}

